\title{
The Credibility of Party Policy Rhetoric Survey Experimental Evidence
}

Pablo Fernandez-Vazquez*

*Postdoctoral Fellow, Juan March - Carlos III Institute, Madrid. Email: pablo.fernandezvz@gmail.com. Website: http://pablofernandezvazquez.com 


\begin{abstract}
This paper analyzes how a party's policy statements affect voters' perceptions of where the party stands on a given issue. I argue that voters do not take a party's statements at face value because these messages can be a strategic tool to win elections. Voters discount popular statements because they may respond to vote-seeking incentives rather than reflect the party's sincere views. Espousing unpopular policies has less instrumental value in obtaining more votes and therefore is more credible. I have tested this argument with a survey experiment fielded in the United Kingdom that exposes respondents to Conservative and Labour Party statements on immigration and the National Health Service. I report evidence that popular statements tend to have a weaker effect on voter perceptions than unpopular ones. This finding suggests a paradox: the more a party needs to change its reputation in order to gain votes, the stronger the voters' skepticism.
\end{abstract}

Keywords: Voter Updating; Party Communication; Spatial Competition; Survey Experiment; Crowd-Sourced Text Analysis; Great Britain.

Supplementary materials are available in an Online Appendix. Replication files are available in the JOP Data Archive on Dataverse (http://thedata.harvard.edu/dvn/dv/jop). All research involving human subjects was conducted in compliance with relevant laws and was deemed exempt by New York University's University Committee on Activities Involving Human Subjects and by Vanderbilt University's Institutional Review Board. 
Politicians spend much of their time making speeches, giving press conferences, and participating in debates. Politicians talk, and some of their messages express views on policy issues. From a normative point of view, this political communication should help citizens make informed voting decisions. Yet, several studies report a weak relationship between changes in the policies that parties propose in their campaigns, as captured in election manifestos, and voter perceptions of party positions (Adams, Ezrow and SomerTopcu, 2011; Fernandez-Vazquez, 2014).

This paper helps account for this weak correlation. I argue that voters do not always take a party's rhetoric at face value because they consider the party's motivation for issuing that message. Specifically, voters discount party statements that are popular with the public because these statements may respond to a vote-seeking strategy rather than reflect the party's sincere preferences. An unpopular statement, in contrast, is less likely to be motivated by the pursuit of votes and thus voters regard it to be a more credible signal of what the party actually stands for. Hence, this paper highlights how the effectiveness of party rhetoric hinges on its credibility (see also Bawn and Somer-Topcu, 2012).

To test this argument, I have fielded two parallel survey experiments in the United Kingdom (UK). Respondents are exposed to actual statements made by the two main political parties, Conservative and Labour. Each respondent places the party on the issue scale before and after observing the statement. The experiments focus on the two most important issues in the UK: Immigration and the National Health Service (NHS). On both issues, a policy option is clearly more popular among voters than the other: a tough immigration policy is more popular than a soft one, and a generous funding of the NHS is more popular than spending controls (Source: April 2016 wave of the British Election Internet Panel Study).

I report evidence that a statement espousing the popular position on the issue tends to have a weaker impact on voter perceptions than an unpopular statement. The difference is more pronounced when the party with stronger vote-seeking incentives adopts the popular 
position. This suggests a paradox: the more a party needs to change its issue reputation, the more skeptical voters are. This finding helps explain why issue ownership tends to be stable (Petrocik, 1996).

\section{Argument}

The seminal work of Downs (1957) highlights how a party's policy statements can be a strategic tool to obtain some goal, typically a greater vote share. These policy statements, moreover, are not binding: Once in office, the winning party can implement different policies (Stokes, 2001). Hence, political parties have incentives to campaign on popular policies in order to obtain more votes, even when these stances do not reflect the party's actual views on the issue. As a result, a party's statement may not be an unbiased signal of what the party actually stands for.

This paper argues that, given the strategic nature of party rhetoric, voters do not take a party's statements at face value. Specifically, voters discount popular statements as less credible than unpopular ones. While a popular stance can be part of a vote-seeking strategy, an unpopular statement has less value in obtaining votes and thus becomes a stronger signal of the party's preferences. As a result, popular statements have a weaker effect on voter perceptions of party positions. The argument implies, moreover, that discounting is more pronounced the stronger the party's vote-seeking incentives to change its image on that issue.

This study focuses on two issues for which UK public opinion has a clear leaning: Immigration and the NHS. For these issues voters can easily identify the most popular policy option. On immigration, most voters favor an anti-immigration policy. On a 0 to 10 scale where 0 means "I prefer many fewer immigrants" and 10 "I prefer many more", 0 is the modal voter preference and 3 is the median. With respect to the NHS, the popular option is to increase funding for this service: most voters consider that cuts have gone too far and the 
service has worsened. ${ }^{1}$ Regarding the two main UK parties, Labour is seen as softer on immigration than the Conservatives and thus faces stronger pressures to change its image. Similarly, the Conservatives are seen as less committed to the NHS than Labour. ${ }^{2}$ Consequently, the argument predicts that voter discounting of popular statements should be deeper for the Labour Party on immigration and for the Conservatives on the NHS.

\section{Survey Experiment}

Two survey experiments were fielded in August 2015, one focusing on immigration and the other on the NHS. Respondents in both experiments are exposed to a real issue statement made by the Conservative Party and another made by Labour. The statement is either pro or anti-immigration in the immigration experiment, pro or anti-NHS in the NHS one. Respondents place the party on the relevant issue scale before and after observing the statement. Placements are measured on a 0-10 scale. For immigration, 0 means "close borders for new immigrants" and 10 means "open borders". For the NHS, 0 means "decrease NHS funding" and 10 means "increase NHS funding".

The statement in each treatment condition was selected using crowdsourcing. First, I identified speeches made by prominent politicians from each party and selected excerpts dealing with immigration flows or NHS funding. Second, I followed Benoit et al. (2016) and crowdsourced the coding of these statements to estimate both the position and the clarity

\footnotetext{
${ }^{1}$ Source: 2015 British Election Study (wave 7). See Online Appendix (section A.1).

${ }^{2}$ The Online Appendix reports the perceived position of Labour and the Conservatives on these issues.
} 
of the message. ${ }^{3}$ The statement selected for each condition has a clear meaning and reflects a distinct position on the issue. Table I presents the immigration statements. ${ }^{4}$

Table I: Statements in each treatment condition. Immigration.

\begin{tabular}{|c|c|c|}
\hline & anti-immigration & $\begin{array}{l}\text { pro-immigration } \\
\end{array}$ \\
\hline Conservative & $\begin{array}{l}\text { "The number of migrants we are seeing is far higher } \\
\text { than our local authorities, our schools and our hos- } \\
\text { pitals can cope with. So many people, so fast, is } \\
\text { placing real burdens on our public services." }\end{array}$ & $\begin{array}{l}\text { "Our openness is part of who we are. We should } \\
\text { celebrate it. We should never allow anyone to de- } \\
\text { monise it. We are Great Britain because of immi- } \\
\text { gration, not in spite of it." }\end{array}$ \\
\hline Labour & $\begin{array}{l}\text { "People want there to be control of immigration. } \\
\text { And I agree. That means strengthening our bor- } \\
\text { ders, with proper entry and exit checks. And we } \\
\text { will introduce those checks." }\end{array}$ & $\begin{array}{l}\text { "Over many centuries Britain has benefited from the } \\
\text { ideas and talents of those who have come here from } \\
\text { abroad. We need migration to get the top talent } \\
\text { and investment we need, for our world class univer- } \\
\text { sities to compete internationally, or to meet skills } \\
\text { shortages in the NHS." }\end{array}$ \\
\hline
\end{tabular}

To capture how respondents interpret each statement, a post-treatment manipulation check asks the participant to place the meaning of the statement on the same 0-10 scale. In addition, the last survey question prompts respondents to identify the popular position on the issue. ${ }^{5}$ With this information I create an indicator variable, popular, which indicates whether, according to the respondent, the party statement reflects the popular position on that issue.

Both survey experiments were administered to a convenience sample of British adults recruited through CrowdFlower, a MTurk-style platform that can enlist survey respondents and compensate them for their participation. ${ }^{6}$ The Online Appendix presents a robustness check ruling out the possibility that the findings of this paper are the product of the nonrepresentative nature of the survey sample.

\footnotetext{
${ }^{3}$ Full results for the crowdsourced coding are reported in the Online Appendix.

${ }^{4}$ The statements selected for the NHS are reported in section A.2 of the Online Appendix.

${ }^{5}$ The item reads: "Irrespective of your own position, what is the option most British citizens espouse?".

${ }^{6}$ Compared to MTurk, CrowdFlower has a superior capacity to recruit participants outside of the USA.
} 
This survey experiment has an advantage over previous observational studies (e.g. Adams, Ezrow and Somer-Topcu, 2011). The design disentangles the discounting of popular statements from two factors that can also explain why party rhetoric may fail to change perceptions: lack of exposure and lack of understanding. Regarding the first factor, respondents are explicitly encouraged to read the party's statement (Mutz, 2011). ${ }^{7}$ Regarding the second, the statements selected for the experiment were previously classified as clear by crowd coders. Relative to the experimental work of Tomz and Van Houweling (2012), moreover, this design maximizes the level of external validity by using actual statements and party labels. Finally, the survey design improves on Lupu (2013) in how it makes it possible to gauge the impact of policy statements controlling for voters' prior perceptions.

\section{Evidence}

I estimate the effect of the policy statement on respondents' perceptions of where the party stands by regressing the post-treatment perception on the pre-treatment perception and the position expressed in the statement. ${ }^{8}$ In order to test the argument that respondents discount popular statements, I interact both the statement position and the pre-treatment perception with an indicator that the statement espouses the popular option on that issue:

$$
\begin{gathered}
\text { post-treatment perception }=\alpha+\beta_{1} \text { statement }+\beta_{2} \text { pre-treatment perception }+ \\
\beta_{3} \text { statement } * \text { popular }+\beta_{4} \text { pre-treatment perception } * \text { popular }+\beta_{5} \text { popular }+\epsilon
\end{gathered}
$$

The variable Statement indicates the issue position expressed in the statement, as interpreted by the respondent. Pre-treatment perception reflects the respondent's opinion before

\footnotetext{
${ }^{7}$ Figure A7 in the Online Appendix reports a screenshot of how the treatment is presented.
}

${ }^{8}$ The Appendix reports manipulation check and across-subject results. 
observing the statement. Logically, the higher the impact of the Statement, the lower the coefficient for Pre-treatment perception because it captures the stability in the respondent's opinion. Popular is a dummy variable defined as follows: For a respondent who thinks that most UK voters are anti-immigration, Popular equals 1 if the statement expresses an antiimmigration position and 0 otherwise. ${ }^{9}$ For a respondent who believes that most voters are pro-immigration, Popular takes the value of 1 if the statement is pro-immigration. ${ }^{10}$ The same rule applies to the the NHS. The argument predicts that popular statements will have a weaker impact on perceptions. Hence, the interaction coefficient for statement * popular should be negative and that for pre-treatment perception * popular should be positive.

Table II reports the regression results. The estimates show that the content of the statement affects the post-treatment perception of the party, particularly for Labour. This is consistent with previous work that shows that policy rhetoric is more effective for opposition parties than governing ones (Bawn and Somer-Topcu, 2012). Most importantly, there is evidence that the magnitude of the impact depends on whether the statement espouses a popular or an unpopular position. For both parties and for both issues, the interaction coefficient statement * popular is negative and pre-treatment perception * popular is positive. This suggests that a popular message decreases the effect of the statement and reinforces the importance of the previous belief. Interaction coefficients are larger in absolute magnitude and statistically significant when the party faces strong electoral incentives to shift positions: the Labour Party on immigration and the Conservatives on the NHS. ${ }^{11}$ To facilitate the interpretation of regression estimates, Figure 1 plots the marginal effect of popular and

\footnotetext{
${ }^{9}$ If the respondent places the statement at 4 or lower on the 0 to 10 immigration scale.

${ }^{10}$ If the respondent places the statement at at 6 or higher on the 0 to 10 immigration scale.

${ }^{11}$ The $\mathrm{p}$ value for all three interaction coefficients marked with the $\dagger$ symbol is 0.06 . These $\mathrm{p}$ values drop below 0.05 if demographic controls are included in the equation (see table A.7 in the Online Appendix).
} 
unpopular statements. Taken together, these results support the argument that voters are less responsive to vote-seeking party statements.

Table II: The effect of popular vs unpopular statements. Regression results.

\begin{tabular}{lcccc}
\hline \hline & \multicolumn{2}{c}{ Immigration } & \multicolumn{2}{c}{ NHS } \\
\hline \multirow{4}{*}{ Statement } & COnSERvative & Labour & COnSERvative & LAbour \\
\multirow{3}{*}{ Statement $X$ popular } & $0.43 *$ & $0.62 *$ & $0.46 *$ & $0.48 *$ \\
& $(0.1)$ & $(0.1)$ & $(0.1)$ & $(0.1)$ \\
Pre-treatment perception & -0.03 & $-0.15 *$ & $-0.17 \dagger$ & -0.1 \\
& $(0.07)$ & $(0.07)$ & $(0.09)$ & $(0.1)$ \\
Pre-treatment perception $X$ popular & $0.35 *$ & $0.37 *$ & $0.50 *$ & $0.35 *$ \\
& $(0.1)$ & $(0.04)$ & $(0.1)$ & $(0.1)$ \\
popular & 0.07 & $0.13 \dagger$ & $0.13 \dagger$ & 0.06 \\
& $(0.08)$ & $(0.07)$ & $(0.07)$ & $(0.08)$ \\
Intercept & -0.16 & 0.4 & 0.4 & 0.4 \\
& $(0.5)$ & $(0.5)$ & $(0.7)$ & $(0.8)$ \\
& $1 *$ & -0.1 & 0.1 & $0.9 \dagger$ \\
$R^{2}$ & $(0.4)$ & $(0.4)$ & $(0.2)$ & $(0.5)$ \\
$\mathrm{N}$ & 0.44 & 0.58 & 0.60 & 0.49 \\
& 452 & 452 & 401 & 401 \\
\hline \hline
\end{tabular}

Standard errors in parentheses. p-values: $\nmid<10 \%, *<5 \%$

The discounting of popular statements has consequences for party competition. The vast majority of respondents agree that an anti-immigration policy and a pro-NHS one are the popular options on these issues ( $86 \%$ and $94 \%$ of respondents, respectively). ${ }^{12}$ Hence, the discounting of popular statements should imply that anti-immigration and pro-NHS statements have a weaker effect on perceptions than pro-immigration or anti-NHS stances. The evidence reported in section A.7 of the Online Appendix confirms this prediction: It shows that anti-immigration and pro-NHS statements (the popular policy options) tend to have a weaker effect on post-treatment perceptions. These differences are statistically significant except for the Conservatives on immigration, a party that is already perceived as

\footnotetext{
${ }^{12}$ The Online Appendix (section A.6) provides further details.
} 
Figure 1: The marginal effect of a policy statement, depending on whether it is popular or unpopular.
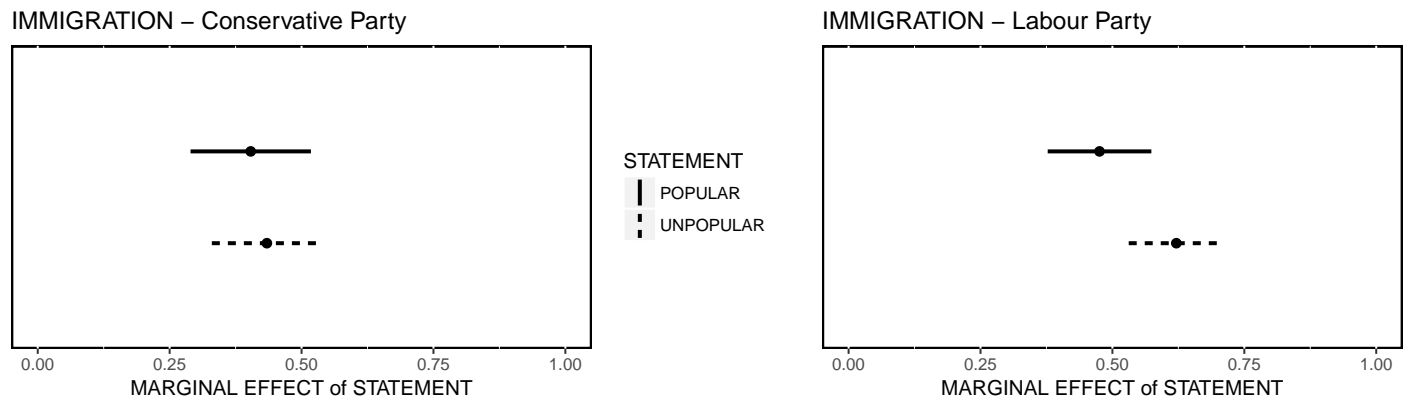

STATEMENT

I POPULAR

UNPOPULAR

NHS - Conservative Party
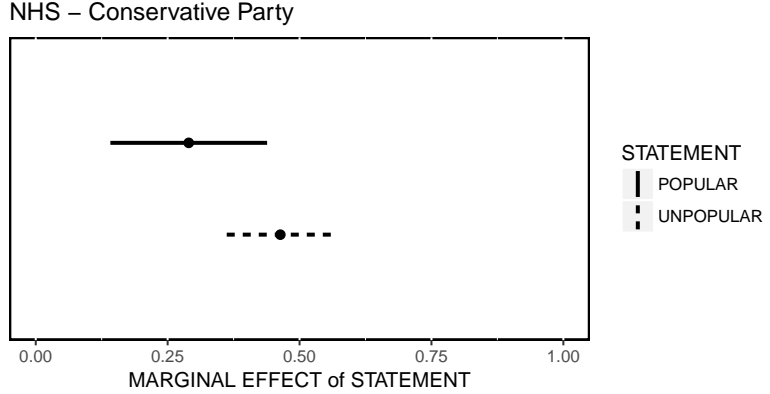

NHS - Labour Party

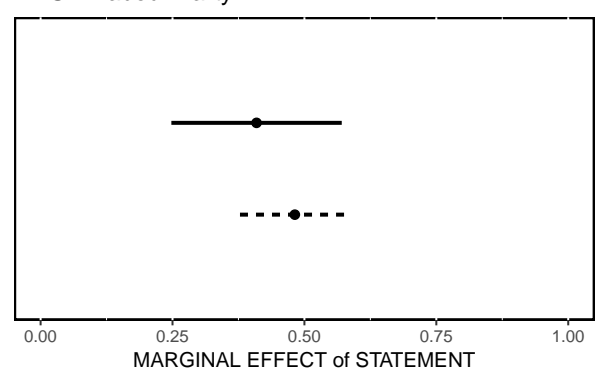

STATEMENT

I POPULAR

UNPOPULAR

tough on immigration and therefore does not face strong vote-seeking pressures to change its reputation.

The Online Appendix presents several robustness checks. I show that the results obtained with this convenience sample can be extrapolated to the UK population as a whole. I also confirm that the findings are robust to specifying several demographic and attitudinal controls, like party identification. Finally, I rule out the alternative explanation that some statements are discounted not because they espouse popular policies, but because they deviate significantly from the party's issue reputation. All these empirical analyses confirm the empirical patterns reported in the main text.

\section{Discussion}

This paper suggests that voters do not take party statements at face value. Popular messages have a weaker effect on perceptions, particularly if the party has vote-seeking incentives 
to change its issue position. Hence, voters take into account the party's motivations when reacting to the party's platform. This supports the argument that voters are more responsive to party behavior that is costly (Fortunato and Stevenson, 2013; Bawn and Somer-Topcu, 2012) and helps explain the stability of party reputations (Dalton and McAllister, 2015).

The discounting of popular statements reduces the capacity of political parties to change their reputation on an issue: The stronger the party's electoral pressures to shift positions, the stronger the voters' skepticism. This identifies a mechanism that helps account for

the stability of issue ownership over time (Petrocik, 1996): The disadvantaged party is constrained in its capacity to credibly shift its issue reputation towards the position of the advantaged party.

A natural extension of this paper is to analyze whether the choice of issue statements has consequences for voters' opinions about the party's valence characteristics. If voters discount popular statements because they may respond to opportunistic motivations, they may also conclude that a party that promises popular policies is less principled than one that expresses unpopular positions. Building on Tomz and Van Houweling (2012), who have shown that candidates that shift positions obtain worse valence evaluations than consistent ones, the testable prediction would be that shifting stances towards the popular option on an issue is more costly for a party's valence than moving towards an unpopular position. The logic of this argument implies that supporting popular policies can paradoxically reduce the ability of the party to get elected.

\section{Acknowledgements}

I am grateful to Eric Dickson, Pat Egan, Jonathan Ladd, Michael Laver, Thomas Meyer, Phil Paolino, Zeynep Somer-Topcu, Lukas Stoetzer, Joshua Tucker, and Simon Weschle, participants in the Perceptions of Party Positions workshop at the University of Texas at 
Austin, and participants in seminars at Rice University and the University of Pittsburgh for comments on previous versions of this manuscript. All errors are my own.

\section{References}

Adams, James, Lawrence Ezrow and Zeynep Somer-Topcu. 2011. "Is Anybody Listening? Evidence that Voters do not Respond to European Parties' Policy Programmes." American Journal of Political Science 55(2):370-382.

Bawn, Kathleen and Zeynep Somer-Topcu. 2012. "Government versus Opposition at the Polls: How Governing Status Affects the Impact of Policy Positions." American Journal of Political Science 56(2):433-446.

Benoit, Kenneth, Drew Conway, Benjamin Lauderdale, Michael Laver and Slava Mikhaylov. 2016. "Crowd-sourced Text Analysis." American Political Science Review 110(2):278-295.

Dalton, Russell J. and Ian McAllister. 2015. "Random Walk or Planned Excursion? Continuity and Change in the Left-Right Positions of Political Parties." Comparative Political Studies 48(6):759-787.

Downs, Anthony. 1957. An Economic Theory of Democracy. New York: Harper \& Row.

Fernandez-Vazquez, Pablo. 2014. "And Yet It Moves The Effect of Election Platforms on Party Policy Images." Comparative Political Studies 47(14):1919-1944.

Fortunato, David and Randolph T. Stevenson. 2013. "Perceptions of Partisan Ideologies: The Effect of Coalition Participation." American Journal of Political Science 57(2):459-477.

Lupu, Noam. 2013. "Party Brands and Partisanship: Theory with Evidence from a Survey Experiment in Argentina." American Journal of Political Science 57(1):49-64. 
Mutz, Diana C. 2011. Population-Based Survey Experiments. Princeton University Press.

Petrocik, John R. 1996. "Issue Ownership in Presidential Elections, with a 1980 Case Study." American Journal of Political Science 40(3):825-850.

Stokes, Susan C. 2001. Mandates and Democracy: Neoliberalism by Surprise in Latin America. Cambridge: Cambridge University Press.

Tomz, Michael and Robert P. Van Houweling. 2012. "Candidate Repositioning." Stanford University and UC Berkeley.

\section{Biographical Information}

Pablo Fernandez-Vazquez is a Postdoctoral Fellow at the Juan March - Carlos III Institute. 28903 Getafe (Madrid) Spain. 